Asian J. Med. Biol. Res. 2019, 5 (4), 237-245; doi: 10.3329/ajmbr.v5i4.45260

\author{
Asian Journal of \\ Medical and Biological Research \\ ISSN 2411-4472 (Print) 2412-5571 (Online) \\ www.ebupress.com/journal/ajmbr
}

Review

\title{
Malnutrition among children raises intimidation to their health in Bangladesh: control strategies
}

Jannatul Nayeem ${ }^{1,3}$ Md. Abdullah Al Mamun ${ }^{1}$, Safayet Sultan ${ }^{1}$, Subir Chandro Ray ${ }^{3,4}$, Tanvir Ahammed ${ }^{2}$ and Shuvho Chakra Borty ${ }^{2,3^{*}}$

${ }^{1}$ Department of Food Technology \& Nutrition Science, Noakhali Science \&Technology University, Noakhali, Bangladesh

${ }^{2}$ Department of Microbiology and Hygiene, Bangladesh Agricultural University, Mymensingh- 2202, Bangladesh

${ }^{3}$ Department of Quality Assurance, Research and Development, Igloo Foods Limited, Kadamtoli, Shyampur, Dhaka, Bangladesh

${ }^{4}$ Department of Food Engineering and Technology, State University of Bangladesh, Dhaka, Bangladesh

*Corresponding author: Shuvho Chakra Borty, Department of Microbiology and Hygiene, Bangladesh Agricultural University, Mymensingh-2202, Bangladesh. Phone: +8801710500560; E-mail: shuvho.micro@gmail.com

Received: 09 September 2019/Accepted: 13 October 2019/ Published: 31 December 2019

\begin{abstract}
Nutritional status of children is a momentous issue across the world. Children are mostly suffering from various infectious diseases, which are ensuing through malnutrition or incommensurable nutritional requirement of children. Household food security, caring practice for women and children, health environment and services and infectious diseases are the major cause of mortality particularly in children in many developing countries. The findings of the review clearly relate malnutrition, which is one of the most underlying causes of infectious diseases among children and existing evidence shows that the prevalence of under-nutrition and other forms of malnutrition among under-five children was high and they are easily affected by infectious disease such as diarrhea, measles, malaria, acute respiratory infection etc.A well-designed social protection system has great potential to improve malnutrition in Bangladesh. The international and domestic evidence presented in this review clearly demonstrates the importance of an integrated approach to tackling malnutrition in Bangladesh. Severe wasting may be reduced by simply improving food intake but tackling chronic malnutrition requires integrated social protection programmes. Programmes that have effectively reduced stunting and wasting have also addressed many of the underlying causes of malnutrition, including improving household food security and the health environment.
\end{abstract}

Keywords: malnutrition; infection; infectious disease; child nutrition status; child-nutrition disorder

\section{Introduction}

Malnutrition is a broad term commonly used as an alternative to undernutrition but technically it also refers to overnutrition. People are malnourished if their diet does not provide adequate calories and protein for growth and maintenance or they are unable to fully utilise the food they eat due to illness (undernutrition). They are also malnourished if they consume too many calories and it is called as overnutrition (UNICEF, 2019). Another term is undernutrition, and it is defined as the outcome of insufficient food intake and repeated infectious diseases. It includes being underweight for one's age, too short for one's age (stunted), dangerously thin for one's height (wasted), and deficient in vitamins and minerals which is also called as micronutrient malnutrition (UNICEF, 2019). 
Nutrition plays a significant role in normal growth and development. Impediments to the access of Macro and micronutrients especially in the rural areas of our country push the immunity of children in suppressive level, thus the infectious diseases become more prone to infect (Sahu et al., 2015). Nutritional deficiencies increase the risk of infection, and weaken every part of the immune system. The increased susceptibility to infections is caused by impairment of immune function by inadequate alimentation. Malnutrition among under-five children is a major public health problem in Bangladesh. This is reflected by the fact that the prevalence of under-weight children in Bangladesh is among the highest in the world, is nearly same as India and doubles that of SubSaharan Africa. It is also observed that the malnutrition problem in Bangladesh is a concentrated phenomenon that is, a relatively small number of districts and villages account for a large share of the malnutrition burden $50 \%$ of villages account for about $80 \%$ of the malnutrition burden (World Bank Report, 2014). Each year approximately 2.3 million deaths among 6-60 months aged children in developing countries are associated with malnutrition, which is about $41 \%$ of the total deaths in this age group (Anderson et al., 1994). A recent study, among children aged between 3 months and 3 years of age conducted in 130 districts through Demographic and Health Surveys in 53 countries over a period from 1986 to 2006 found that — variance in mild under-weight has a larger and more robust correlation with child mortality than the variance in severe under-weight (Bhagowalia et al., 2011). The prevalence of mild under-weight deserves greater attention as a useful signal of changing public health conditions among preschool children in developing countries (Rahman et al., 2009). Therefore, it is important for the health system to detect malnutrition at an early stage for planning and implementing timely interventions at the community level.

Child nutrition status is an important measure of poverty in a population; and poverty, malnutrition and disease are interlinked with each other. Malnutrition in children is the consequence of a range of factors, which are often related to poor food quality, insufficient food intake, and severe and repeated infectious diseases; or frequently it involves some combination of the three (Onis et al., 1993). These conditions, in turn, are closely linked to the overall standard of living and whether a population can meet its basic needs, such as access to food, housing and health care (WHO, 1997). Therefore, child nutritional status assessment not only serves as a means for evaluating the health condition and survival of children but also provides an indirect measurement of the quality of life of an entire population.

Although an inverse relationship exists between anthropometric indicators of nutritional status and mortality, several studies have documented that severely malnourished children are at a much greater risk of dying than others (Gomez et al., 1956 and Schofield et al., 1996). But, an elevated risk of mortality has also been observed by Pelletier et al., 1994 for children at moderate level of malnutrition. When considering the relative proportions of severe versus moderate malnutrition in populations, authors revealed that the majority of nutrition related deaths were significantly associated with moderate level, rather than severe level, malnutrition. For instance, moderate wasting is associated with a mortality rate of 30-148 per 1000 children per year (Chen et al., 1980; Pelletier et al., 1994) and severe wasting is associated with a mortality rate of 73-187 per 1000 children per year (Pelletier et al., 1994). This equates to over 1.5 million child deaths associated with severe wasting and 3.5 million with moderate wasting every year. Therefore, information for both severe and moderate levels of malnutrition is important for policy makers to develop strategies to reduce the overall burden of malnutrition.

In Bangladesh, millions of children suffer from one or more forms of malnutrition. Although Bangladesh has made good progress in the last 2 decades to achieve Millennium Development Goals, MDG-1, the eradication of extreme poverty and hunger and MDG-4 for child mortality, more needs to be done. MDG- 1 and MDG-4 are directly related to nutrition. Improving nutrition status, especially for under-five children is very important to achieve Millennium Development Goal (MDG). Malnutrition rates have seen a marked decline in Bangladesh throughout the 1990's but remained high at the turn of the decade (Chowdhury et al., 2018).

There has been some improvement in child nutritional status over the past decade. The level of stunting among children under age 5 has declined from 51 percent in 2004 to 36 percent in 2014. In the last three years it declined by 5\% points. Wasting increased to 17 percent in 2007 from 15 percent in 2004 and has gradually declined since then, to 14 percent in 2014. The level of underweight has declined from 43 percent in 2004 to 33 percent in 2014 (Black et al., 2008). Present review article discusses the issues and strategies for strengthening service delivery to malnourished children in Bangladesh.

\section{Aim and objective of the review}

Malnutrition is the underlying cause of child morbidity and mortality in Bangladesh. It has not been the priority issue of the development strategies of the government of Bangladesh to overcome the malnutrition in children. The aim of this narrative review is to collate and synthesize the published data to understand the problem as a 
whole. The dearth of studies on child malnutrition in Bangladesh has evoked the researcher to search for and review the existing relevant literature. The specific objectives of this review article were:

(i) to identify about the range of methodologies and methods to access the children malnutrition;

(ii) to highlight the emerging themes to address the children malnutrition;

(iii) to identify the underlying causes of malnutrition in Bangladesh; and

(iv) to discuss and mention about some control strategies.

\section{Materials and Methods}

Malnutrition is widely known as under-nutrition until and unless it is not specified (Shetty et al., 2006). Malnutrition in children is assessed through stunting, wasting, and underweight in children less than five years of age (De Onis et al., 2006). Stunting is chronic malnutrition, underweight is acute malnutrition, and wasting is the combination of acute and chronic malnutrition. Bangladesh has been divided into eight divisions: Dhaka, Chattogram, Rajshahi, Khuna, Barisal, Sylhet, Rangpur and Mymensingh. More than two-thirds of the population of Bangladesh live in rural areas, where the prevalence of poverty is more common. Most of the rural people are engaged in agriculture and agricultural labor, taking care of livestock, and informal business and have the highest prevalence of malnutrition among their children.

In this review paper it is tried to carried out several findings on malnutrition, underlying causes of malnutrition\& infection and take a look at several journals \& reports and all those studies published between 2000 and 2018 in English. As the topic is public health and anthropological relevance, various databases were utilized, including PubMed, Medline, NCBI, CINAHL, Scopus, and social science citation index. A number of keywords and combination of keywords were used to locate the relevant literature, such as "child malnutrition in Bangladesh", "child undernutrition in Bangladesh", "nutritional status of children in Bangladesh", "child health and nutritional status in Bangladesh", and "child health situation in Bangladesh". Furthermore, the list of references of relevant papers was also reviewed to access for more relevant literature on child malnutrition.

These studies establish their research based on the criteria that malnutrition is a major cause of infectious disease and malnutrition increase risk of infection. The case-control study, cohort study and cross section study are selected for those researches. Samples (under-5-year age children) are included in those studies through following some criteria such as; age, nutritional status, other disease and infection conditions etc. Those studies include Anthropometric measurement, which is an important method to measure health status or nutritional status of children. Those studies include a structured questionnaire to collect information on demographic, epidemiological, and clinical characteristics of under 5-year-old children.

\section{Executive summary}

Rates of malnutrition in Bangladesh are among the highest in the world, with six million children estimated to be chronically undernourished (UNICEF, 2009). The decline in chronic malnutrition seen previously - from $60 \%$ in 1997 to $41 \%$ in 2011 - now appears to be slowing down. Policies and practice in Bangladesh need to have a greater focus on nutrition (Ruel et al., 2013), at large scale and across different sectors, in order to accelerate progress on tackling the country's substantial malnutrition burden of $41 \%$ stunting and $16 \%$ wasting (UNICEF, 2009) across a population of 156.5 million (UN, 2013).

Social protection is a human right and a means for states to protect their most vulnerable citizens (UN, 2013). Bangladesh's current social protection system is fragmented and ineffective - in 2010 reaching just 35\% of those living below the poverty line (Kidd et al., 2013). As the Government of Bangladesh leads a significant reform of its National Social Security Strategy, harnessing the potential of social protection for nutrition is vital. As set out in a report of Malnutrition in Bangladesh by Save the Children 2015, a tangible opportunity is presented for the development of social protection to improve malnutrition in Bangladesh. Social protection and nutrition are prominent on the international development agenda, supported by a series of high-level recommendations and commitments. This review particularly complements the International Labour Organization-led Social Protection Floor Recommendation (ILO, 2012), which expresses the commitment of member states for building comprehensive social security systems and prioritising the establishment of national 'floors' accessible to all in need. Our conclusions highlight the importance of an integrated nutrition-sensitive social protection system. This gives weight to arguments to integrate nutrition, alongside a stand-alone goal (Smith et al., 2013).

Many countries have improved nutrition through social protection. Malawi's Mchinji Social Cash Transfer scheme pilot achieved impressive reductions in stunting, which fell from 55\% to 46\% in one year (ODI, 2013). Similarly, Bangladesh's SHOUHADO programme saw stunting rates among 6-24-month-old children fall from $56.1 \%$ to $40.4 \%$ in beneficiary households (CARE, 2012). Achievements in wasting are also notable, as 
Colombia's Familiasen Acción conditional cash transfer programme illustrates, with an average increase of $0.58 \mathrm{~kg}$ for new-born babies in urban areas attributed to better nutrition during pregnancy (Attanasio et al., 2005). Despite a growing international recognition of the impact of social protection, there is still some reluctance on the part of governments to invest funds to develop social protection systems that will effectively tackle malnutrition. Governments must recognise the value of social protection as a 'hand up, not a hand out' for individual beneficiaries and national prosperity. There is also a growing appetite globally to understand the long-term human and economic gains which nutrition-sensitive social protection offers (Smith et al., 2013). This review contributes to the development of this knowledge base, as a crucial step to encourage the investment of domestic resources for social protection to tackle malnutrition. Country-level advocacy must be undertaken because of the local nature of social protection. This report focuses on Bangladesh, and is intended to be the first in a series focusing on countries with high burdens of malnutrition. It is expected that it will make a substantial contribution to the global 'nutrition-sensitive' knowledge base. It forms part of Save the Children's malnutrition and child survival work, to progress the role of nutrition-sensitive approaches and to provide intellectual capacity at national levels for civil society to advocate on specific legislative opportunities. In this review we consider the major pathways to nutrition outcomes and a range of evidence on nutrition-sensitive social protection to make recommendations for policy development and implementation in Bangladesh and for global learning.

We have tried to focus on how developing social protection across the lifecycle, with a greater focus on nutrition behaviour change, adolescent girls, empowering women and the 1,000-day window of opportunity between a woman's pregnancy and her child's second birthday, will help shape healthier and more prosperous futures for everyone in Bangladesh. Social protection, as a nutrition-sensitive approach, has been shown to have an impact on nutrition outcomes by addressing the underlying causes through three main pathways, as illustrated in the table below (The World Bank, 2013). The findings presented in this report are based on international and domestic evidence. They clearly demonstrate the importance of an integrated approach to tackling malnutrition in Bangladesh. Programmes that have effectively reduced stunting and wasting have also addressed many of the underlying causes of malnutrition. We conclude that integrated nutrition-sensitive social protection programmes in Bangladesh should address priority focus areas for nutrition outcomes and across all three pathways.

Table 1. Nutrition sensitive social protection pathway (Mansoor et al., 2015).

\begin{tabular}{|l|l|l|}
\hline Pathway & Importance & How social protection helps \\
\hline $\begin{array}{l}\text { Household Food } \\
\text { Security }\end{array}$ & $\begin{array}{l}\text { Assured access to and consumption of enough } \\
\text { nutritious food for living an active healthy life }\end{array}$ & $\begin{array}{l}\text { Improving income and } \\
\text { increasing assets }\end{array}$ \\
\hline $\begin{array}{l}\text { Caring Practice } \\
\text { for Woman and } \\
\text { Children }\end{array}$ & $\begin{array}{l}\text { Pregnancy and lactation are } \\
\text { critical junctures for quality care and support }\end{array}$ & $\begin{array}{l}\text { Targeting nutritionally } \\
\text { populations through the } \\
\text { approach }\end{array}$ \\
\hline $\begin{array}{l}\text { Health } \\
\text { Environment and } \\
\text { Services }\end{array}$ & $\begin{array}{l}\text { Conditions children's exposure to pathogens and the } \\
\text { use of preventive and curative } \\
\text { healthcare }\end{array}$ & $\begin{array}{l}\text { Promoting improvement, access and } \\
\text { delivery of health and sanitation services }\end{array}$ \\
\hline
\end{tabular}

\section{The underlying cause of malnutrition in Bangladesh}

A number of issues sit behind Bangladesh's high levels of malnutrition. As the population of Bangladesh continues to increase, the number of people who are malnourished will rise unless the following critical areas, which was examined in detail and addressed by Save The Children, 2015. Poverty and inequality are basic (DFID, 2009) drivers of malnutrition in Bangladesh. The gap between the poorest and the richest groups in relation to malnutrition is significant at 28 percentage points (FSNSP, 2011) and must be addressed in order for Bangladesh to truly address its malnutrition burden. Nutrition is closely linked to poverty in Bangladesh, which is widespread and affects the bottom and middle wealth quintiles. The ability to afford a nutritious diet is limited to the wealthier sections of Bangladesh's society.

The underlying causes of malnutrition in Bangladesh manifest at household and community levels across three pathways:

\section{a) Household food security}

Access to food, land and water: In 2011, 69\% of Bangladeshi households experienced some food insecurity (FSNSP, 2011). Bangladesh is densely populated, with land and resources in limited supply. The intensity of the seasons increases vulnerability to limited food access for the poorest, particularly in areas prone to flooding. 
Innovative approaches for resourcing poor areas are needed to allow them to leverage the natural and human resources available to them, increase access to food and achieve more sustainable livelihoods.

\section{b) Caring practices for women and children}

Women's empowerment: Despite progress since 1971 - illustrated by successful family planning and a drastic drop in fertility rates (World Bank, 2007) -women in Bangladesh still have a lower social status than men (BRAC, 2014). This is deeply embedded in cultures and traditions that place greater value on men and boys and that view girls and women as social and economic burdens. Women's status remains low from one generation to the next because of a preference for sons and because daughters have less access to food, health services and education. Women are a vital part of the solution of improving nutrition in Bangladesh, and therefore more attention must be given to empowering women (BRAC, 2014).

Stunting at birth: Around 20\% of babies in Bangladesh are born stunted (Save the Children, 2011). Girls who marry young typically give birth at younger ages. Giving birth at a young age increases the risk of intra-uterine growth retardation (poor growth of a baby while in the womb), leading to stunting at birth. Child marriage leads to girls dropping out of education and restricts their social development. It perpetuates an unequal society, enhancing female vulnerability. Child marriage, early pregnancy and stunting at birth are critical points for malnutrition across the lifecycle (Save the Children, 2015).

\section{c) Health environment and services}

Health access: Across Bangladesh, there is low spending on healthcare, a weak public health system and widespread poverty (Adams et al., 2013).

Urbanisation: Bangladesh is experiencing rapid urbanisation. Urban populations have expanded rapidly and are expected to increase by a further 50\% by 2028 (NIPORT, 2013). The implications for nutrition are deeply concerning. One-third of the urban population currently live in slums, where many environmental factors negatively affect health and nutrition. In 2013 the stunting rate was 50\% in the worst-affected urban areas. By 2038, the majority of people in Bangladesh will live in urban areas (Hoddinott et al., 2013).

\section{Malnutrition and infectious diseases}

Malnutrition is a general term which is caused by an improper or insufficient diet. It most often refers to undernutrition. Under-nutrition refers to inadequate consumption, poor absorption, or excessive loss of nutrients, but the term Malnutrition can also refer over-nutrition which is resulting from overeating or excessive intake of specific nutrients.

Infection is the invasion of an organism's body tissues by disease causing agents, their multiplication, and the reaction of host tissues to these organisms and the toxins they produce. Infectious disease, also known as transmissible disease or communicable disease is illness resulting from an infection.

Malnutrition is particularly lethal in combination with infectious diseases such as acute respiratory infection, malaria, measles, diarrheal diseases. These diseases are the major killer diseases affecting children.

Diarrheal diseases: Diarrhea associated with malnutrition is probably the commonest cause of death in young children worldwide. Every year around 10 million children under 5 die. 5 million from malnutrition about 2 million with diarrhea (Bridget and Fenn, 2009).

Measles: Measles is a highly infectious respiratory disease that can cause pneumonia, brain damage and death. Malaria: Malaria is a global health problem which can cause hemolysis, which in turn causes anemia. Often affects poor and malnourished populations and vulnerable groups are children.

Tuberculosis: Tuberculosis (TB) is a chronic infection. This infection is mainly influenced by under-nutrition. Acute respiratory infection (ARI): Pneumonia often affects children with LBW or those whose immune systems are weakened by malnutrition or other diseases.

\section{Malnutrition increases the risk of infection}

Severe malnutrition during childhood affects thymic development, which compromises immunity in children by a long-term reduction of peripheral lymphocyte counts. This immunodeficiency represents a key factor in susceptibility to infections and has therefore been termed nutritionally acquired immunodeficiency syndrome. Diminished immune functions render undernourished patients more susceptible to infections (Ulrich and Kaufmann, 2007). 


\section{Control strategies}

A well-designed social protection system has great potential to improve malnutrition in Bangladesh. The international and domestic evidence presented in this review clearly demonstrates the importance of an integrated approach to tackling malnutrition in Bangladesh. Severe wasting may be reduced by simply improving food intake but tackling chronic malnutrition requires integrated social protection programmes. Programmes that have effectively reduced stunting and wasting have also addressed many of the underlying causes of malnutrition, including improving household food security and the health environment. Effects are greater when efforts are accompanied by infrastructural improvements that enable participants to access safe water and use sanitary latrines. Bangladesh has made great progress in this area.

Demonstrating the importance of caring practices for women and children, behaviour change communication (BCC) and the education of caretakers (male and female) about proper child feeding practices, nutrition and hygiene has also been linked to substantial improvements in child nutrition. The stark underlying causes of malnutrition in Bangladesh related to undernourished pregnant women, child marriage and stunting at birth highlight the importance of BCC and education as part of an integrated approach for nutrition-sensitive social protection. Specific focus should be given to changing eating practices during pregnancy, to delaying pregnancy and to BCC for the whole family (particularly men).

The pathways approach taken in this review demonstrates the potential of social protection for nutrition, yet issues arose on a number of occasions in relation to limited data. This is a result of ineffective monitoring and evaluation of nutrition-sensitive social protection programmes. Well-designed programmes with clear indicators are required. Stunting in Bangladesh is 'bad for everyone' and closely linked to widespread poverty. Therefore, a narrowly targeted poverty programme, as is currently proposed in the National Social Protection Strategy, is not going to sufficiently address chronic malnutrition. Policy and decision-makers in Bangladesh should recognise the value of integrating nutrition into social protection. Immediate opportunities are available with the vulnerable group development (VGD) programmes. Strengthening the 'hand up, not a hand out' approach can help prevent the intergenerational transmission of poverty, inequality and undernutrition.

Generally, malnutrition is caused by lack of nutritional components it can be prevented by providing special diet such as fruit, vegetable, milk product, oils, meat and beans etc. with sufficient amount in timely. There are several prevention measures for malnutrition (Edem et al., 2015). Some studies show that inadequate/lack of antenatal care was associated with malnutrition. This implies that mothers of malnourished children were less likely to have had adequate health contacts through antenatal visits. A study held in three Latin American countries which found only a weak association between antenatal care and reduction in the level of child health (Forero-Ramirez et al., 2014). They attributed these findings to differences in the quality of care and health inequalities. Antenatal care provides opportunities for nutritional counseling which mothers of well-nourished children may have benefited from and it has been shown to be effective if there is food security (Bhutta et al., 2013). A majority of the mothers must have nutritional counseling or advise from the health service which is one of the interventions expected in a national plan (Brantuo et al., 2009 and Bryce et al., 2009).

Since maternity care is free in all government health institutions, pregnant women should be encouraged to access antenatal care and the health service should engage those mothers who miss out through home visiting. However, a more specific and targeted approach will be needed. Vitamin A supplementation was not associated with malnutrition even in the univariate analysis. Although Vitamin A reduces child mortality, it is not known to affect anthropometric measurements (Bhutta et al., 2008).

\section{Discussion}

Childhood malnutrition is still a leading public health concern in Bangladesh and many other countries. Rates have gradually fallen in recent year. The prevalence of malnutrition is still considerable. Malnutrition like under-nutrition and over-nutrition can increase the risk of infectious diseases and can cause child death. Malnourished children have greater susceptibility to infections of the gastrointestinal tract and bacterial respiratory infection.

High-level political commitment and leadership is essential. Nutrition must be integrated across

all ministries, not just those responsible for health and nutrition. A useful first step would be to integrate SMART nutrition indicators, informed by the common results framework being developed by the UN Food and Agriculture Organization (FAO), the World Food Programme and others to inform the Government of Bangladesh's next Five-Year plan.

There must be continued development of multi-sector mechanisms to allow civil society to provide effective technical assistance to support the strengthening and expansion of social protection for nutrition. To reflect nutrition-sensitive priorities and to embed nutrition-sensitive social protection, national nutrition forums and 
mechanisms need to be extended to include social protection specialists. This is particularly important for the Scaling Up Nutrition (SUN) movement. The recommendations and implications raised in this report need to be considered in the development of Bangladesh's National Nutrition Services and the National Social Security Strategy of Bangladesh, and in the drafting of the Government of Bangladesh's next Five-Year Plan.

\section{Strength and limitation of this study}

This is the first study to review the range of methodologies and identify the neglected geographical areas and widely used methods of previously published papers assessing child malnutrition in Bangladesh. This research will be helpful for further researchers to design their methodology and target population before conducting their research. This study highlighted methodological gaps: preferred techniques for assessing the child malnutrition, varied study designs, and tagged the geographical areas with human development index rating. However, there are some limitations in this study because the previously published papers were published in different time spans, varied types of populations were under-studied, the varied age groups of the children, the small sample sizes, and different natures of the studies. One-fourth of the studies reviewed in this research had sample sizes of less than 200, and it is very difficult to generalize the result of these small-scale studies. The studies reviewed in this research had the three types of the population groups i.e., community-based, hospital-based, and schoolbased studies. There was much variation in results of all three types of population, and it was difficult to draw conclusion about the causes of child malnutrition. Therefore, it is suggested that the future studies must be clear in the methodological stage for the selection of the homogeneous studies in term of target population, type and nature of the study, and sample size for better understanding the problem under investigation. There is a need for more research with a more homogeneous approach to know the current real situation of child malnutrition in a socio-cultural and demographic context.

\section{Conclusions}

In conclusion, direct significant associations between malnutrition and severity of infectious diseases were noted. The interactions between malnutrition and infection and the determinants that provoke increased susceptibility to gastrointestinal and bacterial respiratory infections in children of different areas of Bangladesh. There is dearth of qualitative and mixed-method studies on the causes of child malnutrition in Bangladesh. In terms of geographical area covered, most of the studies were conducted in the rural areas, whereas densely populated urban areas were largely neglected by researchers. The prevalence of all types of malnutrition in Bangladesh was found to be higher than the global threshold value. It was found that malnutrition starts at an early age and remains persistent at later stages. Most of the researchers employed the anthropometry technique i.e., wasting (weight-for-height), stunting (height-forage), and underweight (weight-for-age) by the WHO for assessment of child nutritional status. The most vulnerable age group of children (6-23 months) was entirely neglected to exclusively study infant and young child feeding practices. It was clearly evident that higher intensity of child malnutrition prevails in the rural areas of Bangladesh. Early marriages, large family size, high fertility rates with a lack of birth spacing, low income, and the lack of breastfeeding and exclusive breastfeeding were found to be major determinants of child malnutrition.

\section{Recommendations for future studies}

It is suggested that further studies should focus on the causes of malnutrition in the infancy stage to strengthen the nutritional status of children and that the neglected areas should also be studied to highlight this problem. The major causes of child malnutrition are also associated with the mother's reproductive health care behaviour, maternal diet, and autonomy. It is therefore suggested that further research also study the maternal factor while exploring the causes of child malnutrition. There is also a need to know about the diet and type of food that mothers prefer to give their children while exploring the causes of child malnutrition. Therefore, it is also suggested that the dietary diversity (DD) recall method should also be utilized to know about the preferred food that mothers give to their children. The component of micronutrients deficiency was entirely omitted under discussion of the previously published research. It is recommended that the micronutrient assessment should be a component of future research for a better understanding of the type of malnutrition. There is also the dire need of qualitative and mixed-method research to understand and highlight the cultural and lifestyle factors that cause child malnutrition in Bangladesh.

\section{Conflict of interest}

None to declare. 


\section{References}

Adams AM, T Ahmed, SE Arifeen, T Evans, T Huda and L Reichenbach, 2013. Innovation for universal health coverage in Bangladesh: a call to action. The Lencet 382: 2104-2111.

Anderson JC, R Manas and RG Schroeder. A theory of quality management underlying the Deming Management Method, 1994. Aca. Manag. Revw. 19: 117-125.

Attanasio M, JK Francklin, MN Doz, H Keffedmen and J Hopkins, 2005. The Short-term Impact on development rises intimidation on child health. Egy. Jour. Fo. Sci. 46: 112-121

Bhagowalia P, SE Chen and WA Masters, 2011. Effects and determinants of mild underweight among preschool children across countries and over time. Econ. Hum. Biol., 9: 66-77.

Bhutta ZA, T Ahmed, RE Black, S Cousens, K Dewey and E Giugliani, 2008. Interventions for maternal and child undernutrition and survival. The Lancet, 371: 417-440.

Bhutta ZA, JK Das, A Rizvi, MF Gaffey, N Walker and S Horton, 2013. Evidence-based interventions for improvement of maternal and child nutrition: what can be done and at what cost? The Lancet, 382: 452-477.

Black MH, TH Raddish, M Hocking, J Davidson and N Hopper, 2008. Assessment of developmental parameters of children of South America. Jour. Trop. Med. 13: 1123-1136

BRAC, 2014. Perspectives on Women's Rights: Feminist Voices from Bangladesh, Public Event. Available: http://www.brac.net/latest-news/item/659-perspectives-on-women-s-rights-feminist-voices-from-bangladesh

Brantuo MNA, W Okwabi, S Adu-Afuawuah, E Agyepong, NT Attafuah and G Brew, 2009. Landscape analysis of readiness to accelerate the reduction of maternal and child undernutrition in Ghana. SCN News, 37: 31-37.

Bridget F and Fenn T, 2009. Malnutrition in humanitarian emergencies. London school of hygiene and tropical medicine. 22 (11): 75-98.

Bryce J, D Coitinho, HI Darnton, D Pelletier, PP Andersen, 2009. Maternal and child undernutrition: effective action at national level. The Lancet. 371: 510-526.

CARE, 2012. Reaching new heights: the case for measuring women's empowerment. Available: https://www.care.org/sites/default/files/documents/CARE_IWD_2012.pdf

Chen H, J Ghung, M Susang, W Diching and F Ma, 1980. Assessment of growth parameters during zero to five years of children of central China. Chin. Jour. Nat. Sci. 22: 26-35.

Chowdhury MH, NM Faijun, J Ferdous, N Sultana and N Pattanayek 2018. Prevalence and risk factors of child malnutrition in Bangladesh. Res. Rev. J. Statistics Math Sci., 4: 65-76.

De Onis M., AW Onyango, E Borghi, C Garza and H Yang, 2006. WHO Multicentre Growth Reference Study Group Comparison of the World Health Organization (WHO) Child Growth Standards and the National Center for Health Statistics/WHO international growth reference: Implications for child health programmes. Public Health Nutr., 9: 942-947

DFID, 2009. Statistics for international development. Available: https://assets.publishing.service.gov.uk/ government/uploads/system/uploads/attachment_data/file/67720/final-printed-sid-2009.pdf

Edem M. A. Tette, Eric K. Sifah and Edmund T. Nartey, 2015. Factors affecting malnutrition in children and the uptake of interventions to prevent the condition, BMC Pediatr., 15 (11): 189.

Forero-Ramirez N, LF Gamboa, A Bedi and R Sparrow, 2014. Child malnutrition and prenatal care: evidence from three Latin American countries. Ame. Jour. of pub. hea. 35: 163-171.

Franca TGD and LLW Ishikawa, 2009. Impact of malnutrition on immunity and infection. A. J. Venom. Anim. Toxins incl. Trop. Dis. 15: 16-28.

FSNSP, 2011. Food Security and Nutritional Surveillance Project. Available: http://sph.bracu.ac.bd/index.php/research-project/115-nutrition/366-foodsecurity

Gomez SC, A Desouza, K Heterson, I Indranarayan and J Franklin, 1956. Feeding children properly has an effect on growth. Fron. Nutri. 8: 26-35.

Hoddinott J, H Alderman, JR Behrman, L Haddad and S Horton, 2013. The economic rationale for investing in stunting reduction. Matr. Chi. Nutr., 9: 69-82.

ILO, 2012. Social protection floors recommendation on world of work report. Available: https://www.ilo.org/wcmsp5/groups/public/---dgreports/---dcomm/---publ/documents/publication/wcms _179453.pdf

Kidd S, B Khondoker, M Anderson, S Tamang and J Fernandes, 2013. Scoping Report on Poverty and Social Protection in Bangladesh. Amer. Jour. Fo. Nutr. 44: 123-134

Mansoor A, M Giasuddin, J Ali, F Ahmed and R Sultana, 2015. Malnutrition in Pakistan: severest in region. Intl. Jour. Fo. Sa. Sec. 11: 176-185 
Naila BA, M Rahbar, Z Bhutta and S Badruddin 2006. Child's gender and household food security are associated with stunting among Pakistani children residing in urban squatter settlements. Food and Nutrition Bulletin 27: 114-27

NIPORT, 2013. Bangladesh Urban Health Survey. Available: https://www.measureevaluation.org/ resources/publications/tr-15-117

NIPRT, 2011. Bangladesh: Demographic and Health Survey. Available: https://dhsprogram.com/pubs/ pdf/PR15/PR15.pdf

ODI, 2013. Social protection and resilient food system, Overseas Development Agency. Available: https://www.odi.org/projects/2739-social-protection-and-resilient-food-systems

Onis PG, D Methew, S Tamang, D Bhatiya and K Sundaram, 1993. How undernutrition induces diseases on children under five years. Jour. Trop. Medi. 22: 223-233.

Pelletier MJ, S Squitz, M Kulseder and K Zeows, 1994. Factors responsible for mental health development of refuge childrens of Somalia. Jour. Prev. Med. 11: 107-116.

Rahman K, T Rajaraman, M Singh, J Foster and T Cheng, 2009. Malnutrition affects the proper growth of urban children of densely populated cities of China. Jour. Popi. Sci. 19: 122-134

Ruel MT, H Alderman, J Thompson and A Thomas, 2013. Nutrition-sensitive interventions and programmes: how can they help to accelerate progress in improving maternal and child nutrition. The Lancet. 16: 226-238

Sahu SK, SG Kumar, BV Bhat, KC Premarajan, S Sarkar, G Roy and N Joseph 2015. Malnutrition among under-five children in India and strategies for control. Jour. Natr. Sci. io. Med. 6 (1): 18-23

Save the Children, 2011. Visual leadership for children: annual review 2011. Available: https://resourcecentre.savethechildren.net/node/14974/pdf/annualrep_2011.pdf

Save the Children, 2015. Malnutrition in Bangladesh. Available: https://bangladesh.savethechildren.net /news/malnutrition-bangladesh-new-report-published

Schofield MR, N Joseph, T Nickolas, M Sony and J Henderson, 1996. Factors of child growth affecting national development. Jour. F. Sci. Nutr. 16: 86-94

Shetty P, MN Hasan, Z Singh, N Chahal and S Singh, 2006. Malnutrition and undernutrition. Medicine, 34: 524-529.

Smith LC, F Khan, TR Frankenberger and A Wadud, 2013. Admissible Evidence in the Court of Development Evaluation? The Impact of CARE's SHOUHARDO Project on Child Stunting in Bangladesh. Wor. Devep., 41: 196-216.

The World Bank, 2013. Improving nutrition through multisector approach: social protection briefing. Available: http://documents.worldbank.org/curated/en/490101468326706674/Improving-nutrition-throughmultisectoral-approaches-social-protection

Tulsi RB and C Muniraj, 2013. Nutritional status of under five-year children and factors associated in Kapilvastu District. Nepal. Journal of Nutritional Health \& Food Science. 17: 122-134

Ulrich ES and Kaufmann SH, 2007. Malnutrition and infection: complex mechanisms and global impacts; PLoS Med., 4: 115.

UN, 2013. World Population Prospects: The 2012 Revision. Available: https://www.un.org/en/development/ desa/publications/world-population-prospects-the-2012-revision.html

UNICEF, 2009. Advancing child-sensitive social protection. Available: https://www.unicef.org/aids/ files/CSSP_joint_statement_10.16.09.pdf

UNICEF, 2019. Malnutrition rates remain alarming: stunting is declining too slowly while wasting still impacts the lives of far too many young children. Available: https://data.unicef.org/topic/nutrition/malnutrition/

WHO, 1997. Conquering suffering, enriching humanity. Available: https://www.who.int/whr/1997/en/

World Bank, 2007. The Global Family Planning Revolution. Available: https://populationmatters.org/ solutions?gclid=Cj0KCQiA04XxBRD5ARIsAGFygj9XLL7tXm0imB1cemvxXmz61bzO0V8by7zGcFov1G 2hHek5GpVr2MAaAl8PEALw_wcB

World Bank, 2014. Promoting Opportunity, Growth and Prosperity. Available: https://www.worldbank.org/ content/dam/Worldbank/AR14_OperationalHighlights.pdf 